\title{
Colorectal Inflammatory Polyp
}

National Cancer Institute

\section{Source}

National Cancer Institute. Colorectal Inflammatory Polyp. NCI Thesaurus. Code C5680.

A non-neoplastic polypoid lesion in the colon and rectum. It may arise in a background of inflammatory bowel disease or colitis. It is characterized by the presence of a distorted epithelium, inflammation, and fibrosis. 